\title{
INTERNACIONALIZAÇÃO DA PÓS-GRADUAÇÃO EM ENFERMAGEM
}

A divulgação da produção científica está consolidando oportunidades inéditas para uma nova perspectiva de acesso aos profissionais e pesquisadores na atualidade. A aprendizagem mútua, a valorização pública da saúde e o reconhecimento da necessidade de mudança nos modos como produzimos e divulgamos o conhecimento tem contribuído para a qualificação dos periódicos científicos.

Num contexto em que o conteúdo científico produzido por pesquisadores em diferentes lugares do mundo é imediatamente disponibilizado para grandes parcelas da população acadêmica, ampliam-se os locais onde é possível obter as informações e conhecimentos necessários para a tomada de decisões clínicas e populacionais. O aumento explosivo não só no volume total de informações, mas também na facilidade de acesso a elas, implica repensar o papel das universidades, em particular, dos programas de pós-graduação.

A próxima geração de pesquisadores, capazes de extrair, sintetizar e aplicar o conhecimento já requisita a formação de redes de pesquisas com foco na qualidade da produção científica. A criação destas redes, vinculadas à pós-graduação, induz à internacionalização das instituições universitárias brasileiras.

Paradoxalmente, os movimentos globais de pessoas, tecnologias e saberes não têm sido acompanhados de igual compromisso com o financiamento público da circulação dos novos processos e produtos produzidos pelos cientistas no mundo todo. Cada vez mais esse processo de internacionalização do conhecimento tem sido financiado pelos próprios pesquisadores, com custos cada vez mais difíceis de serem suportados por indivíduos ou pequenos grupos de investigação.

As Instituições de Ensino Superior, em especial os programas de pós-graduação, possibilitam parcerias e, consequentemente, a criação e expansão de redes internacionais entre diversos países, focalizadas no aprimoramento da qualidade da produção acadêmica. Desse modo, a internacionalização da Pós-Graduação em Enfermagem, especificamente, tornou-se um desafio permanente, no sentido de promover, sobretudo, uma expansão qualitativa do corpo de pesquisadores, enfatizando a mobilidade internacional de docentes e discentes e a produção científica de qualidade e impacto na realidade social. ${ }^{1}$ A possibilidade de obtenção do título de doutor em duas instituições (cotutela) ou coorientações de mestrado e doutorado, convênios com universidades estrangeiras, e organização de eventos internacionais itinerantes são exemplos de ações nessa direção.

Experiência local nesse sentido deu-se com a criação e implantação de dois grandes projetos do Programa de Pós-Graduação em Enfermagem da Universidade Federal de Santa Catarina. O primeiro, a implantação do Mestrado Interinstitucional Internacional realizado na cidade de Magallanes em Punta Arenas no Chile, iniciado em março de 2017. O segundo, a criação do Laboratório de Relações Internacionais em Saúde e Enfermagem \& Ciência e Tecnologia, uma iniciativa em conjunto com o Curso de Graduação em Enfermagem. Tais projetos e parcerias, com instituições universitárias e organismos de diversas partes do mundo, contribuem com a difusão de uma imagem institucional contemporânea e dinâmica, preparada para interagir com outros povos e culturas na busca de inovação e desenvolvimento humano.

A editoração e a divulgação da produção científica em âmbito internacional constituem, também, uma abordagem institucional desafiadora. Os componentes para uma equação de sucesso compreendem alcançar medidas de impacto, que denotem a qualidade das publicações e ampliem o público consumidor, leitor e autor. O impacto de periódicos, medido por indicadores e índices bibliométricos internacionais, expressa a crescente relevância da comunicação científica. Os indicadores representam padrões de desempenho, contudo é preciso cautela em sua análise, visto que tais medidas são externas à realidade brasileira. ${ }^{2}$

Ainda que não haja uma relação diretamente estabelecida, o movimento de acesso aberto, aliado à adoção da publicação em língua inglesa, tem favorecido a expansão de fronteiras nacionais, ampliando a visibilidade e a relevância da ciência brasileira. 
Por fim, as exigências para a internacionalização e os esforços dos programas de pós-graduação para seu alcance guardam mérito, especialmente sob uma perspectiva de integração cultural, social, política e econômica, formando profissionais capacitados para a globalização e enfrentamento das diferenças entre os países.

\section{REFERÊNCIAS}

1. Milena Y. Internationalization of graduate education in Brazil: rationale and mechanisms. Educ. Pesqui [Internet]. 2018 [cited 2018 Mar 03]; 44:e161579. Available form:: http://www.scielo.br/scielo.php?script=sci_ arttext\&pid=S1517-97022018000100303\&lng=pt\&nrm=iso

2. Nassi-Calò L. A miopia dos indicadores bibliométricos [Internet]. SciELO em Perspectiva, 2017 [cited 2018 Mar 28]. Available from: http://blog.scielo.org/blog/2017/06/01/a-miopia-dos-indicadores-bibliometricos/

\section{Jussara Gue Martini}

Doutora em Enfermagem. Coordenadora do Programa de Pós-Graduação em Enfermagem (PEN) da Universidade Federal de Santa Catarina (UFSC)

\section{Eliane Regina Pereira do Nascimento}

Doutora em Enfermagem. Subcoordenadora do PEN/UFSC

\section{Selma Regina de Andrade}

Doutora em Enfermagem. Editora-chefe da Revista Texto \& Contexto Enfermagem 